\title{
Narrative Music, Visuals and Meaning in Film
}

Johnny Wingstedt

Royal College of Music, Stockholm, Sweden

Sture Brändström and Jan Berg

Luleå University of Technology, Dept. of Music and Media, Piteå, Sweden

\begin{abstract}
Narrative media music, music used for narrative purposes in multimedia such as film, television or computer games, is becoming one of the largest sources of musical experience in our daily lives. Though typically experienced on an unconscious and unreflected level, this kind of music actively contributes narrative meaning in multimodal interplay with image, speech and sound effects. Often, what we (think we) see is to a large degree determined by what we hear. Using Halliday's (1978) metafunctions of communication as a starting point, two short film scenes (from Jaws and The Secret of My Success) are examined, with a focus on the intermodal relationships of music and image. The examples illustrate how musical and visual expressions combine to form multimodal statements where the whole is certainly different than the sum of the parts.
\end{abstract}

Keywords: Film music, Metafunctions, Multimodality, Musical semiotics, Narrative music.

The emergence of new digital media is having a profound effect on how we communicate, how we make meaning and perceive the world. Kress (2003) describes how the screen is replacing the book as the dominant medium for communication. The centuries-long dominance of writing is giving way to a new dominance of the image, which in recent years has led to an increased interest in exploring principles of visual meaning-making, literacy and learning through visual means (e.g. Kress \& van Leeuwen, 2006; Lindstrand, 2006; van Leeuwen \& Jewitt, 2001). The new conditions for communication via the screen is however not restricted only to visual modes of communication. Today, the screen is usually not silent. Besides image we are also making sense, or trying to make sense, out of the intricate interplay with aural modes such as spoken language, sound effects and music. Each mode individually 
bears meaning, but above all meaning emerges from their complex multimodal interplay. As Walter Murch remarks, talking about film sound in his foreword to Michel Chions book Audio-Vision (1994): 'Despite all appearances, we do not see and hear a film, we hear/see it' (p. xxi).

This article will take a closer look at some of the functions of narrative media music, music used for narrative purposes in film, television and computer games etc - and discuss how meaning is achieved in interplay with the visuals. This will be done by examining the multimodal interplay of music and image in two short movie-scenes, using Halliday's (1978) metafunctions of communication as a point of departure. Narrative media music is becoming one of the largest sources of musical experience in our daily lives. Even if this kind of music tends to be transparent and is often processed by the audience on an unreflecting level, it seems to actively contribute to how we make meaning from a multimodally told story. Gorbman (1987) describes it: '[the music] guides the spectator's vision both literally and figuratively' (p. 11). In other words - what (we think) we see is to a large degree determined by what we hear.

It of course also works the other way around. Just as the music will affect how we see things, the visuals will also determine how we hear the music. Murch (in Chion, 1994) describes a phenomenon he calls conceptual resonance between image and sound, where the sound makes us see the image differently, and then this new image makes us hear the sound differently, which in turn makes us see something else in the image and so on. As audience however, our conscious attention is usually on the visuals. We tend to interpret the events on film or television as something we see - even if we in fact actually 'hear/see' it. This is reflected also in how we talk about media experiences: we go to see a movie, we watch television and so on. For the sake of analysis however, emphasis will in the following primarily be put on music's contribution to how meaning is established in the multimodal interplay of the filmic narrative. A social semiotic perspective will be used, and especially Kress and van Leeuwen's (2006) book Reading Images: The Grammar of Visual Design has provided inspiration, fundamental concepts and terminology. 
A musical starting point has been Wingstedt $(2004,2005)$ who suggests a categorization of musical narrative functions such as they appear in film and other multimedia. Six classes are presented, which will here simply be referred to as functions:

- The Emotive function refers to music's ability to communicate emotive qualities, either experienced by the audience (induced) or just cognitively identified (represented; Juslin, 2001). The expressed emotions may be attributed to individual characters of the story or represent relationships or events - they can also describe overall emotive aspects of situations or forebode future implications of the plot.

- The Informative function comprises situations where music expresses or 'explains' phenomena or events by communicating information on a cognitive rather than on an emotional level. Music can for example evoke certain cultural settings or time periods, clarify ambiguous situations, indicate social status or simply represent a character or phenomenon, for instance by the use of a leitmotif (this will be further discussed later).

- The Descriptive function is related to the informative function in certain aspects, but differs in that the music is actively (or programmatically) describing something rather than more passively representing certain values. It is usually a matter of describing the physical world, such as physical setting, appearance or movement.

- The Guiding function includes musical functions that, so to speak, turn directly to the audience aiming to 'direct' the eye, thought and mind. This could include indicative or imperative functions. The latter function is prominent in computer games or advertising, where the purpose is to bring the audience to perform specific actions.

- The Temporal function foregrounds the time dimension of music. Especially important is music's ability to provide continuity (immediate, longer or overall) as well as how music can contribute and define structure and form.

- The Rhetorical function refers to how music sometimes 'steps forward' to comment the narrative events or situation. This is often achieved by having the musical expression contrast the visuals or by referring to well-known musical material.

In a given situation, different musical narrative functions typically operate simultaneously on several different levels; the salient functions will quickly and dynamically change. 


\section{Metafunctions}

In order to make it possible to examine the interactions between music and visuals in film more closely, and to put the musical narrative functions into a wider communicational perspective, Halliday's (1978) metafunctions of communication will be used as a starting point. Simply put, the metafunctions are based on the notion that: (1) Every sign tells us something about the world; (2) It positions us in relation to someone or something; (3) It produces a structured text (Jewitt, 2006). Using Halliday's terminology, these three basic functions are known as the ideational, the interpersonal and the textual metafunctions respectively. According to Kress, Jewitt, Ogborn and Tsatsarelis (2001) the metafunctions are to be seen as 'general requirements of any human communicational system' (p. 4).

The ideational metafunction is the content function of communication. Kress et al. (2001) describe it as representing what goes on in the world; material, verbal, mental and relational processes - 'who does what, with or to whom and where' ( $p$ 13). The interpersonal metafunction is the participatory function of communication, communication as doing something. It is the component through which the communicator expresses her own attitudes and judgments - and seeks to influence the attitudes and behaviour of others. It establishes, maintains and specifies relationships between members of societies or groups through expression of social relations, interrelations of power and knowledge (ibid.). The textual metafunction is the component which provides the texture, the organizing of a text (in a broader sense) as a coherent message through textual resources of a mode (in relation to the environment). The textual component has an enabling function with respect to the other two. It is only in combination with textual meanings that ideational and interpersonal meanings are actualized (Halliday, 1978: 113). A modal expression is an instantiation of all three functions interwoven.

The issue of musical meaning has been controversial and much discussed over the years, especially when it comes to music's ability to represent ideational meaning. Advocates of the idea of 'absolute' or 'autonomous' music have argued that (especially instrumental) music is not capable of expressing any specific meaning, except the meaning of the musical sound itself (e.g. Hanslick 1955/1854). It can however be asked if music is ever by 'itself'. The context may be more or less clear, but from a social semiotic point of view it is impossible to think about music without a social, cultural and situational setting including also the 
multimodal interplay involved in any musical performance - be it live or recorded. This has also been discussed in depth by Cook (1998).

Van Leeuwen (1999) has pointed out the difficulties in applying Halliday's metafunctions to sound as a general mode. He suggests that this is maybe because the resources of sound does not seem as specialized as those of language and vision, maybe because sound is not yet to be considered a communicational mode. Trying to look at sound as one distinct mode of expression seems to be an overwhelming challenge, since the wide domain of sound can encompass so many different forms of expressions. However, looking at the much narrower domain of narrative media music, the communicative aspects become clearer. This has several reasons. Firstly, the historical, social and cultural practices connected to the use of music in narrative multimedia such as film are well established in Western society. Also, a musical underscore for film is typically composed with an explicit narrative purpose.

Furthermore, the situational, narrative and multimodal contexts in film are usually relatively clear. According to social semiotic theory, an expression's contextual relationship is inseparably connected to how we make meaning. Hodge and Kress (1988) for example, state that 'the context, both the physical referents and the social conditions of semiosis, is decisive for communication to occur' (p. 39). If the context in which music occurs (and contributes) is perceived as being vague and ambiguous, the meaning-making process will be similarly vague and ambiguous. In film however, the musical expression occurs in a relatively welldefined and distinct multimodal context. The interplay of the music with visuals, dialogue, sound effects etc, provides conditions for the music to actively and concretely contribute to the narrative. Also, the typical filmic narrative relies to a large degree on socially and culturally established conventions, which contributes to making the musical narrative functions clear and 'readable' to members of that culture (although specific meanings may be realized differently for individual members).

Wingstedt, Brändström and Berg (2008) and Wingstedt (2008) have studied how, among other factors, previous media habits are related to knowledge and understanding of musical narrative functions. The participants of a study demonstrated strong consensus regarding knowledge of general musical narrative functions in multimedia, which were clearly evident and readable to them. At the same time they however expressed notable individual variations concerning specific narrative meanings, treating meaning potentials and affordances of music 
in ways related to their individual backgrounds and interests. This illustrates how the general narrative context can be regarded as being relatively clear at the same time as potential meanings, as realized for individual listeners/viewers, are still open to negotiation.

\section{Jaws Example}

A short scene from the movie Jaws (1975), directed by Steven Spielberg, will here be used to illustrate how the concept of metafunctions can be applied as a point of departure when analyzing a musical dramatic underscore. When analyzing a multimodal text, such as film, the metafunctions can be applied to the different modes individually, as well as to the whole multimodal ensemble. In this case it is primarily the latter approach that will be taken, in order to explore the interactions between the music and the other modes involved. The following scene takes place about 25 minutes into the movie, and lasts for ca 90 seconds:

It is a quiet summer night and we see two men standing on a small wooden pier by the sea. Musically, in the underscore, a mildly dissonant chord is quietly building. The men are fishing, and we understand they are going for a big fish since they are using a car tire for a float and a thick metal chain as a fishing-line. Suddenly something takes the bait and we can see the chain disappear into the water as the float is dragged away. At the same time a musical motif is heard in the underscore. It is a melodic interval of a minor second, played by low strings, repeating relentlessly. The float and the chain keep moving further out into the water. The men get excited and shout: 'He's taking it, he's taking it!' The chain is attached to the pier, and suddenly the wooden construction collapses from the strain put on it. One of the men falls into the water and part of the pier is dragged outwards following the chain. After a short while we can see the floating pier suddenly turning around. It is now coming towards the man swimming in the water. As this happens, the musical expression changes, the downbeats are heavily accented and the music gets louder. The man swims for his life. The tempo of the music speeds up, and the image intercuts between shots of his struggle and the pier getting closer to him. He manages to reach safe ground just before the creature dragging the pier gets to him. The music slows down, the rhythmic activity evens out, it gets softer and ends on a long note. The man is now safe. 
The musical content for this entire scene is based on the (now) famous Jaws leitmotif, composed by John Williams. In its most basic form it is a two-note motif of an alternating minor second interval that is used to represent the shark. By the time this scene appears in the movie, a connection has been well established between the motif and the creature, since the shark has already appeared several times - each time accompanied by the same motif. The motif has played only when the shark is directly referred to. Through consistent repetition and association it has gradually acquired a certain meaning, and this way of using it is what makes it a 'true' leitmotif: a recurring musical motif that is associated with a particular character, object, relationship, place or idea etc. The concept of leitmotif was developed and refined primarily by the German composer Richard Wagner (1813-1883), and in order for a musical theme in film to be considered a leitmotif 'one must observe a clear and consistent relationship between a musical idea and its onscreen counterpart' (Hickman, 2006: 43).

\section{Jaws: Music's Ideational Aspects}

A basic characteristic of any leitmotif is that its meaning could be described as being 'cumulative'. The first time the Jaws leitmotif is heard in the film its function is not yet established. For each recurrence the motif will however gradually transform into a sign that explicitly represents the shark. The statement of the motif in the scene described above thus communicates ideational information necessary for this scene: 'Jaws is present'. Interestingly, the shark is not visible in this scene, only what might be interpreted as signs of its actions which the leitmotif helps to make clear. The leitmotif coming to represent Jaws (and subsequently 'danger', 'evil' etc) can be seen as a musical symbolic attributive process and can also be ascribed to the Informative function of narrative music mentioned above. Kress and van Leeuwen (2006) list several characteristics of symbolic attributes, one being that 'they are made salient in the representation', another being that 'they are pointed at' (p. 105). A leitmotif is made salient by repetition and association. The recurrent use of the same musical material makes it gradually easier to recognize and thereby to notice. The leitmotif is 'pointed at' by its consistent placement together with the phenomenon it is set to represent, in this case Jaws (at the same time as it is also 'pointing to' the phenomenon). Through this, a 'relation of identity' is established. The meaning-making processes of the leitmotif are in this way similar to how we learn to associate a visual logo with a certain product, brand or institution. But just as a logo is not arbitrarily chosen but is also carefully designed to express certain values regarded to be appropriate or desirable associations, so is a leitmotif usually composed to as ably as possible describe or characterize the phenomenon it is representing. 
The Jaws motif contributes such descriptive meanings through sound by associating certain possessive attributes with the beast (the carrier). The low register of the motif suggests large size and power in a way that a higher register would not. By experience we know that large objects are required to produce sounds in the bass register, an example of what van Leeuwen (2005) refers to as experiential metaphor. The low register can also be associated with the physical position of the shark lurking beneath the surface of the water. Still another association would build on a convention of film music that low notes express danger, violence and menace. The repeating rhythmic movement of the music describes another attribute of the shark - the relentless movement of its tail, which Williams himself has said to be the initial idea behind this motif (Bouzereau, 2000). The instrumentation of bowed strings suggests a gliding motion through the water, providing a dark and glum timbre. The rhythmic movement also stresses the dissonant melodic interval of a minor second. A dissonant interval is usually defined as being unstable, harsh and unresolved. Dissonance does in itself suggest potential movement towards resolution, and in this case it also seems to emphasize the unstable, primitive and ruthless nature of the beast.

At the point where the pier turns and start coming towards the swimmer, the simultaneous changes in the music (accented downbeats, louder dynamics and increased tempo) lets us know about Jaws' determination and intention. We can hear how the shark is firmly determined to catch its prey, which can be understood as a 'mental attribute' of Jaws. It can also be seen as what Kress and van Leeuwen (2006) call a mental process, which is a 'vector formed by a "thought bubble" or a similar conventional device [that] connects two participants, the Senser and the Phenomenon' (p. 75, our italics). The vector in this case would be replaced by the synchronization between the music and the image. The Senser is represented by Jaws, in turn jointly represented visually by the pier being dragged and musically by the leitmotif. The Phenomenon is represented musically by the accented downbeats, dynamics and increased tempo.

Kress and van Leeuwen (ibid.) also describe narrative processes where the ideational relation between an Actor and a Goal in an image is established through a vector - and how in film the role of the vector is taken over by movement. A complication is however that the relation between Actors and Goals may be represented in several subsequent shots, each showing only one of the participants, resulting in a disconnection typical for contemporary 'film language'. 
In the Jaws scene the sequence of shots alternating between the swimming man and the approaching pier is an example of this. One function of the music in this case is that it contributes to somewhat bridging the disconnection. It establishes a pronounced sense of impetus - we can still hear the shark even when we see the shots showing only the swimming man. This reinforces the vector between the Actor and the Goal in the separate shots as it connects them and adds direction and momentum. The accented downbeats and the increasingly faster tempo of the music further underline this function.

It seems clear that the music is not only capable of expressing ideational meanings, but also does this on several simultaneous, and dynamically shifting, levels. The Actor (Jaws) is in this scene visually deleted but musically represented by the leitmotif in interplay with the image of the moving piece of the pier (and the float). At the same time the music is active in defining conceptual symbolic as well as analytical processes.

This scene illustrates some important aspects of the interplay of visuals and music, which provide conditions for the music to actively and expressively contribute to the overall narrative. The initial meaning potential of the music is relatively open, determined by the material affordances and constraints of the musical sound as well as social and cultural conditions. Through the multimodal interplay of music and image the musical meaning becomes more specific, which enables it to actively and expressively contribute to the narrative. It becomes apparent how the narrative meaning emerges from the 'intermodal' processes in interplay with the contexts involved.

\section{Jaws: Interpersonal Aspects}

The interpersonal metafunction, the participatory function of communication addresses questions of relationships and purposes of the participants involved in the communicational act, and thereby also aspects of power, modality (degrees of truth), attitudes, agency etc. Kress and van Leeuwen (2006) distinguish between interactive participants and represented participants:

The former are the participants in the act of communication - the participants who speak and listen or write and read, make images or view them, whereas the latter are the participants who constitute the subject matter of the communication; that is, the people, places and things 
(including abstract 'things') represented in and by the speech or writing or image, the participants about whom or which we are speaking or writing or producing images (p. 48).

The interpersonal processes of the musical narrative functions discussed here can be seen as primarily taking place between interactive and represented participants - between the audience member and the film. Before looking closer at the musical narrative functions at work on the interpersonal level, it first has to be discussed who the involved interactive participants are in film communication. The viewers (or rather listeners/viewers) can maybe be loosely defined as 'the audience', even if that is both a hazy and complex definition. From the producers' side there might be attempts at defining a 'target audience' or 'imagined audience' but the viewer will still remain a relatively anonymous concept from this point of view. Chatman (1980) suggests the term 'implied reader' as well as 'implied author'. Various studies exploring different aspects of audience responses illuminate the complexity of the audience concept, showing how factors such as age, gender, ethnicity, schooling, family situation, media habits, interests etc relates to attitudes and meaning-making processes of the individual listener/viewer (e.g. Barker \& Brooks, 1998; Hodge \& Tripp, 1986; Wingstedt et al., 2008).

Equally complex and hazy is usually the viewer's idea about who is the producer(s) of the musical score in a film. Seldom is the musical underscore distinguished from the other aspects of the movie, making the issue of determining the musical communicator(s) vague and unreflected - just as the music itself is often experienced on an unconscious and unreflected level, de-emphasizing the listener's awareness of any specific 'musical communicator'. The implied author might be - more or less consciously - associated with different participants (one specific or a combination of several), such as the film director, the movie company or television network, the executive producer, the writer, the composer, the performing actors, even characters of the narrative or the rather indistinct notion of 'the film itself'.

Looking at some of the basic intentions of most films, the purpose to tell a story is usually evident. In the case with the Jaws scene it seems likely that the aim is to express suspense, to entertain, to achieve immersion or to frighten the audience. To do this, music's emotive dimension is important and it is also made use of here, as described above. The emotive dimension however works on several different levels. Juslin (2001) makes a distinction between emotions being experienced by the listener (induced emotions) or emotions simply 
being recognized (represented or observed) as such on a more cognitive level. In the latter case, we're speaking of ideational informative or descriptive functions. However, if the feeling of danger is induced and felt by the audience, the function is instead interpersonal, an emotive process going on between the film (and its makers) and the audience member. In a viewing situation the experiencing of a scene is typically a mixture of the two - often with one of the functions being more salient at a given moment.

At the very start of the Jaws scene, there is a short moment of 'introductory' music, a dissonant chord quietly building. The music is at first kept in the background, partly masked by other sounds. The foreboding nature of this music subtly prepares the audience, in a manner that can be understood as providing a prediction using future tense - an 'offer of information' of what is to come (Kress \& van Leeuwen, 2006: 123). As soon as the thumping leitmotif starts, it is however clearly audible getting more into the aural foreground - and it stays that way for the rest of the scene. This is done without really having to increase the volume, since the frequency spectrum of the music is now not colliding with the other sounds, not even when the men start shouting - a technique sometimes referred to as audio interleaving (Jägerskogh, 2002). It is as if the music is discretely making itself available for listening - in a sense corresponding to what Kress and van Leeuwen (2006) call an offer. By doing this at the same time as the float starts moving, the music also helps to call attention to what is going on visually. It not only ideationally represents the shark, but also at the same time performs an indicative function - on an interpersonal level alerting the audience to look.

Despite the strong emotive impact of this music, we never really get 'inside' or close to the shark. The music is here not used to portray the inner mental processes of Jaws. We are not to identify with the beast (as for example Max Steiner's music in the 1933 version of King Kong makes us do; Palmer, 1990), its psychological processes remain obscure. Rather than inner attributes, the music emphasizes the outer - letting us feel the size, power, movement, unpredictability and vicious intentions of the shark. These attributes are then what the audience is placed in relation to. This, in combination with Jaws' invisibility, contributes to installing a fear of the unknown, of the uncontrollable - where the audience has to imagine what is not represented.

At the same time the musical expression is congruent with the overall narrative. The level of involvement is high, the music almost naturalistically and with close attention to detail setting 
out to paint elaborate nuances of Jaws' physical attributes, movement and temperament. This heightens immersion as well as modality. The music convinces us to accept and believe in what is happening. Actually, the visuals alone in this scene are not really expressing much excitement or suspense, but in combination with the music and the overall narrative the expressed events become immersive and believable. In film, music is often used this way, to achieve high modality, to heighten the emotional credibility - what Gorbman (1987) describes as lowering the audience member's 'thresholds of belief' (p. 6)

\section{Jaws: Textual Aspects}

When it comes to the textual aspects of music much has been written over the years, not least in fields such as musicology and music cognition (e.g. Meyer, 1956; Cooke, 1959; Temperley, 2001). Most often though, the focus has been on musical structure with little concern to social, cultural, situational or multimodal contexts - a notable exception being van Leeuwen's (1999) exploration of the semiotic potentials of speech, music and sound. In discussing the interactions between music and visuals, it is however not primarily music's internal ('intramodal') structures that will be of interest here, as much as the intermodal processes at play.

A fundamental feature of the multimodal design in the Jaws scene is the placement of the musical sound in relation to the overall narrative structure. This has several implications. To start with, the musical underscore in the scene is nondiegetic, meaning that it is not part of the spatio-temporal world of the story told - not heard by the represented participants but only by the audience. This is, of course, common practice of the musical underscore in film, the accepted convention. Still, as Donnelly (2005) remarks, this practice is remarkable and 'a most notable anomaly in the system' (p. 12). Using the music as something that is 'not-real' in relation to the diegesis, however opens up for certain meaning-making narrative practices not available with diegetic music. In a scene like this for example, with the use of an orchestral leitmotif representing the shark, making the music diegetic would not be an option - if nothing else so for reasons of narrative realism. Donnelly (ibid.) suggests that nondiegetic music is given "something of a supernatural character, where it is closer to "the voice of God", the transcendent or the supernatural' (p. 13). The nondiegetic position of the music makes it possible to aurally communicate and illustrate phenomena, both physical and abstract, that don't actually make sounds. In this case we can hear Jaws' movements and physical as well as mental attributes without having to consider the diegetic source of the aural representation. 
The placement of the music in a world different from the world depicted by the story becomes a framing device that marks a disconnection of the music from the other narrative modes representing the told world (image, dialogue, sound effects). But as the individual modes are narratively disconnected, they are at the same time temporally simultaneous. Through editing as well as musical composition, the music is carefully placed and timed with the visuals and the other aural elements. The temporal alignment between modes becomes a crucial element of establishing meaning - including whether the music at all is present or not, also making the 'musical silence' a carrier of meaning (Lipscomb \& Tolchinsky, 2005). Kress and van Leeuwen (2006) describe how in film the synchronization between the dialogue track and lip movements on screen takes the role of a vector, connecting Speech and Speaker, similarly to how dialogue balloons represent speech in still images. In a similar way, the synchronization between music and image functions as a vector connecting the visuals with the musical sound - establishing a joint 'meaning potential basis'. Chion (1990) relates to this phenomenon using the term synchresis (combining the two words 'synchronicity' and 'synthesis'), referring to how visual and auditory elements that are synchronized will be perceived as one unity: 'The spontaneous and irresistible weld produced between a particular auditory phenomenon and visual phenomenon when they occur at the same time' (p. 63). It is this kind of textual weld that enables the ideationally informative and descriptive representations of Jaws, as well as the interpersonal processes described above. While Chion mainly refers to relatively exact instances of synchronization, such as footsteps or lip sync, it is apparent that simultaneity also in a looser sense sparks persuasive meaning-making mechanisms.

The technique of audio interleaving, making room for the leitmotif, was mentioned earlier. This technique as well as the changes in volume, the accented downbeats and increased tempo described - are different ways of achieving musical salience. Not necessarily to draw conscious attention to the music itself, but to enhance musical clarity and thereby making the relations to the visuals and other narrative elements more articulate. Salient aural elements will typically be associated with simultaneously salient visual elements and form multimodal instances of joint meaning.

An important textual meaning-making function of music is how it establishes continuity - the ability of music to provide a sense of temporal coherence to the multimodal weave. Through rhythmic, harmonic, melodic and timbral devices, music contributes a temporal flow, which 
forms rhythmical relationships on many simultaneous levels and between the different semiotic modes available. Music makes time audible. Visually, the Jaws scene is represented through a collection of shots containing various kinds of movement; participants falling, floating, breaking, swimming - as well as fast camera movements in various directions. The individual shots are all from different angles with different size of frame - and cutting between the shots is made in a relatively high tempo. The musical sound provides an immediate continual structure that connects the individual cuts and helps the viewer to make sense of the visual jumble. A longer continuity is also established that keeps the entire scene together, giving it a heightened sense of unity. Discussions of how rhythmical relationships contribute cohesion within and between semiotic modes, and are articulated on several simultaneous levels, can be found in for example Martinec (2000) and van Leeuwen (1985, 1999, 2005).

The music in the Jaws scene is also textually expressing a formal shape that can roughly be described as: intro, exposition, climax and coda. This musical form is enhancing and defining the dramatic form for the whole scene - which is like a very short Aristotelian (or Freytagian) drama containing exposition, climax and resolution. Another way to see this can be to look at the exposition, represented musically by the basic leitmotif, as the Given - according to Kress and van Leeuwen (2006), 'what we already know'. From there we are taken to the climax (the accented downbeats), the New (that 'which is not yet known'). This New turns into another Given, taking us further to a second New, the slowing down and ending on a safe long note.

Intermodal textuality is of course not only about simultaneity. Coherence is also achieved in relation to what has happened before, to intertextuality, the relationship between separate utterances. If, within a film, each scene is looked at as somewhat separate texts, the cumulative meaning-making process characteristic for a leitmotif is depending on the intertextual progression of the scenes containing the motif. Furthermore, the repeating of the leitmotif throughout the film also has the textual function of contributing overall continuity and unity to the entire production. If the Jaws leitmotif later is heard in different situations or in other movies, this will also have consequences for the meaning-making processes for those who have seen the original movie Jaws (see the next example). Similarly - a reflection often heard about the Jaws leitmotif is that it bears a striking resemblance to Igor Stravinsky's ballet music The Rite of Spring. The Jaws motif may because of this be associated with aspects more 
or less consciously attributed to Stravinsky's music, such as 'primitive forces' or 'pagan rituals'.

\section{Musical Commenting}

The use of music in the Jaws scene exemplifies some of the musical narrative functions suggested initially, such as the emotive, informative, descriptive, guiding and temporal narrative functions. These functions are simultaneous, but their relative salience will continuously and dynamically shift in interplay with the other narrative modes involved. The different expressional resources offer a wide range of potential meanings that can turn more or less specific according to the listeners'/viewers' interests, and situational and socio-cultural contexts. Meanings will also dynamically transform according to the multimodal processes described. Replacing the music in this scene or even shifting the same music by just a few frames in relation to the visuals will create new intermodal relationships, suggesting different readings.

Similarly, using the same music in different visual and narrative contexts will uncover entirely different potentials for meaning. To illustrate this, let's look briefly at a scene from the film The Secret of My Success (1987, directed by Herbert Ross):

The main character, Brantley Foster (Michael J. Fox) is about to be seduced by his boss's wife, Vera Prescott (Margaret Whitton). They are in her luxurious garden, and the scene starts as Brantley, dressed in shorts, jumps into the swimming pool. He appears a little uneasy about the situation. Vera, in a sexy bikini, follows with an elegant dive. The musical underscore starts playing. It is a two-note motif played by low strings. As the couple starts playing around in the water, the music develops. It's the Jaws' leitmotif. Brantley is slightly bewildered when Vera pulls off his shorts. The musical downbeats get heavily accented. Brantley vainly tries to get his trunks back, as Vera mischievously teases him and starts to remove her bikini top. The water sprays and splashes as they vigorously tumble around. In the music a dramatic crescendo culminates with a low note 'stinger', synchronized with a shot of the wet bikini hanging from a small cherub statue by the pool. 
The music in this scene is virtually the same as the music in the Jaws' scene described before, but its meaning is totally different. One possible reading of the scene is that the contrast between the playfulness of the situation and the serious and dramatic music creates a humorous effect. The use of the Jaws leitmotif here relies on the assumption that the audience knows the movie Jaws and is familiar with the music. The intertextual associations make us compare Vera to the ruthless shark, which can be seen as contributing humour to the scene (one of several available readings). On the interpersonal level the music is here given a commenting role, producing a distancing perspective. It is almost as if someone was looking into the camera giving the audience a knowing and ironic wink. In this sense the music is doing the equivalent of what Kress and van Leeuwen (2006) describe as a demand demanding 'that the viewer enters into some kind of imaginary relation' (p. 118). This is also an example of the rhetorical function mentioned earlier. Creating intermodal contrast is an often used method to achieve rhetorically commenting functions. Lipscomb \& Tolchinsky (2005: 396) point out how the use of musical contrast can invite intellectual processing and active participation from the audience. The scene illustrates how the meaning of the music changes depending on the context.

The concluding 'stinger' (an accented singular note or harmony, usually synchronized with a visual event or used to emphasize a reaction to a dramaturgical turn), is here used indicatively to (interpersonally) point to the wet bikini. It 'rhythmicizes' the visuals at the same time as it comments, tongue-in-cheek, the not-shown activities of the now bikini-less Vera.

\section{Diegetic Music}

In the examples discussed so far the music is used non-diegetically. Thus, there is no narratively implied demand to account for its sound source. This is facilitated by music's generally high degree of representational abstraction. It can certainly be made to represent quite specific and concrete phenomena, as we could see in the Jaws scene, but essentially music is to be seen as an abstract form of communication. A musical expression in film will seldom be taken for concretely being a 'genuine recording of reality' in the way that sound effects may be perceived - except when the aim is to represent 'someone playing music'. Kress and van Leeuwen (2006) point out that 'the more abstract the sign, the greater its semantic extension [...] the greater its potential range of uses as a signifier in signs' (p. 54). Maybe herein lies much of the reason for music's readiness to express such a wide and multilayered spectrum of possible meanings. Music's seemingly endless ability to combine 
and blend with image and other forms of expression builds on its highly abstract affordances, which in film is also what allows for its high extent of nondiegetic usage. A relatively abstract level of expression makes more room for the listener's creative meaning-making activity, providing a higher potential for narrative immersion.

When the music in film is diegetic, sometimes referred to as source music (as the source of the music is shown or implied as being present in the spatiotemporal world of the story) the communicational conditions will somewhat change. There will be consequences for the meaning-making processes on the ideational and interpersonal as well as the textual level. Source music will typically be used in similar ways as ambient sound effects, to contribute aural atmosphere or realism to a setting or situation in the story - such as a radio playing music in the background or a band playing dance-music at a party.

Ideationally, diegetic music will be perceived as simply being (part of) the physical environment, rather than non-diegetically describing it. The informational value will concern the fact that (in this situation/environment) there is music playing. This will in turn contribute to our understanding of the situation, just as other diegetic features such as dialogue, ambient or synchronized sound effects, physical setting, clothes, hairstyles etc, will. An interpersonal aspect of diegetic music is how it has a tendency of becoming transparent to the listener. Once established as being diegetic, the audience will be inclined to take it for granted - and this will contribute to the music, and thus its narrative functions, often being even less consciously prominent to the listener than nondiegetic music is.

On a textual level, diegetic music will introduce some new parameters, which in turn will also affect ideational and interpersonal dimensions. One such textual parameter concerns the actual music examples or genres that are used in specific situations. When composing or using music for nondiegetic purposes, consideration is usually made with respect to the film's overall style, instrumentation, use of motifs etc. With diegetic music different considerations are made. Important aspects will be how the music fills its diegetic purpose, aspects of authenticity and situational relevance will usually be essential. This can for example result in the use of well-known music pieces, which might not be appropriate if the music was nondiegetic. Synchronization to movement is another textual aspect that will follow somewhat different principles when the music is diegetic. The impression here will often be that the music initiates movement, or that the movements follow the music (such as when we 
see people dancing or marching to music) - while tightly synchronized nondiegetic music will rather be perceived as expressing or describing movement, as when using mickey-mousing (musically expressing or imitating physical movement, usually synchronized to onscreen action).

Diegetic music is sometimes used with what Chion (1990) calls an anempathetic function, i.e. being 'indifferent' to the dramatic situation - resulting in a contrasting or commenting role. However, diegetic music is also often simultaneously used for more specific narrative purposes, according to the narrative functions discussed with nondiegetic music - a technique sometimes known as source scoring. At times music in film will glide between diegetic and nondiegetic functions, blurring the line between the two.

\section{Conclusion}

Kress and van Leeuwen (2006) point out how our sense of sight is generally considered more reliable than our sense of hearing and they comment on how 'seeing has, in our culture, become synonymous with understanding' (p. 163). As the above examples show however, there is in narrative multimedia more to see than meets the eye. When image, dialogue, sound effects and music combine into multimodal texts, a 'chemical reaction' seems to take place. The resulting whole is, if maybe not greater, certainly different than the sum of the parts. The communicational act takes place on several levels and through many simultaneous channels or modes, but our experience is perceived as being one. Since such experiences often are interpreted as being of primarily visual nature the effect is, as stated initially, that what (we think) we see is to a large extent determined by what we hear.

The emerging multimodal possibilities of new media affect most aspects of modern society, including how we learn, how we work and how we play. New media also emphasize 'the fact that all meaning-making is in its nature multimodal' (Cope \& Kalantzis, 2000: 211). Acknowledging the narrative impact of music in multimodal storytelling such as film, television or computer games, it will be of increasing importance to further explore how musical elements combine in aural statements that in turn combine with visuals and other narrative modes to form multimodal expressions. Looking at narrative media music as maybe the largest source of musical experience in our daily lives, it is clear that a better understanding of its meaning-making functions is of great importance. 


\section{References}

Barker, M. \& Brooks, K. (1998). Knowing Audiences: Judge Dredd, Its Friends, Fans and Foes. Luton: University of Luton Press.

Bouzereau, L. (Writer/Director/Producer). (2000). 'The Making of Jaws' [DVD Documentary]. On Jaws: Anniversary Collector's Edition [DVD Motion Picture]. United States: Universal Studios Home Video.

Chatman, S. (1980). Story and Discourse: Narrative Structure in Fiction and Film. Ithaka, NY: Cornell University Press.

Chion, M. (1994). Audio-Vision: Sound on Screen. New York: Columbia University Press.

Cook, N. (1998). Analysing Musical Multimedia. Oxford: Oxford University Press.

Cooke, D. (1959). The Language of Music. Oxford: Oxford University Press.

Cope, B \& Kalantzis, M (2000). 'Designs for Social Futures', in B. Cope \& M. Kalantzis (eds.) Multiliteracies: Literacy Learning and the Design of Social Futures, pp. 203-234. London: Routledge.

Donnelly, K.J. (2005). The Spectre of Sound: Music in Film and Television. London: BFI Publishing.

Gorbman, C. (1987). Unheard Melodies: Narrative Film Music. Bloomington, Indiana: Indiana University Press.

Halliday, M.A.K. (1978). Language as a Social Semiotic. London: Edward Arnold.

Hanslick, Eduard (1955). Om det sköna i musiken [On the Musically Beautiful; orig. Vom Musikalisch-Schönen, 1854]. Uppsala: Schismens skriftserie 1.

Hickman, R. (2006). Reel Music: Exploring 100 Years of Film Music. New York: Norton.

Hodge, R. \& Kress, G. (1988). Social Semiotics. Cambridge, UK: Polity Press.

Hodge, R. \& Tripp, D. (1986). Children and Television: A Semiotic Approach. Cambridge: Polity Press.

Jewitt, C. (2006). Technology, Literacy and Learning: A Multimodal Approach. London: Routledge.

Juslin, P.N. (2001). 'Communicating Emotion in Music Performance: A Review and a Theoretical Framework', in P.N. Juslin and J.A. Sloboda (eds.) Music and Emotion: Theory and Research, pp. 309-337. Oxford: Oxford University Press.

Jägerskogh, A. (2002). Visst ska det höras vad dom säger och sjunger? [Of course what they say and sing should be heard?]. Unpublished manuscript, Royal Institute of Technology, Stockholm.

Kress, G. (2003). Literacy in the New Media Age. London: Routledge.

Kress, G. \& Van Leeuwen, T. (2006). Reading Images: The Grammar of Visual Design, $\left(2^{\text {nd }}\right.$ edition). London: Routledge.

Lindstrand, F. (2006). Att göra skillnad: Representation, identitet och lärande i ungdomars arbete och berättande med film [Making difference: Representation, identity and learning in teenagers' work and communication with film] (Doctoral dissertation). Stockholm: HLS Förlag. 
Lipscomb, S.D. \& Tolchinsky, D.E. (2005). 'The Role of Music Communication in Cinema', in D. Miell, R. MacDonald \& D.J. Hargreaves (eds.) Musical Communication, pp. 383-404. Oxford: Oxford University Press.

Martinec, R. (2000). 'Rhythm in Multimodal Texts'. Leonardo, Vol. 33, No. 4, pp. 289-297.

Meyer, L.B. (1956). Emotion and Meaning in Music. Chicago: University of Chicago Press.

Palmer, C. (1990). The Composer in Hollywood. London: Marion Boyars Publishers.

Temperley, D. (2001). The Cognition of Basic Musical Structures. Cambridge: The MIT Press.

Van Leeuwen, T. (1985). 'Rhythmic Structure of the Film Text', in T.A. Van Dilk (ed.), Discourse and Communication: New Approaches to the Analysis of Mass Media Discourse and Communication, pp. 216-232. Berlin: De Gruyter.

Van Leeuwen, T. (1999). Speech, Sound and Music. London: Macmillan.

Van Leeuwen, T. (2005). Introducing Social Semiotics. London: Routledge.

Van Leeuwen, T. \& Jewitt, C. (eds.) (2001). Handbook of Visual Analysis. London: Sage Publications.

Wingstedt, J. (2004). 'Narrative Functions of Film Music in a Relational Perspective', paper presented at ISME - Sound Worlds to Discover, Santa Cruz, Tenerife, 14-16 July.

Wingstedt, J. (2005). Narrative Music: Towards an Understanding of Musical Narrative Functions in Multimedia (Licentiate thesis). Luleå: School of Music, Luleå University of Technology, Sweden. (Available at http://pure.ltu.se/ws/fbspretrieve/199292)

Wingstedt, J. (2008). Making Music Mean: On Functions of, and Knowledge about, Narrative Music in Multimedia. (Doctoral dissertation). Luleå University of Technology, Dept. of Music and Media.

Wingstedt, J., Brändström, S. \& Berg, J. (2008). 'Young Adolescents' Usage of Narrative Functions of Media Music by Manipulation of Musical Expression'. Psychology of Music, Vol. 36 (No. 2): pp. 193-214. 